\title{
Development of a Voltammetric Assay, using Screen- Printed Electrodes, for Clonazepam and Its Application to Beverage and Serum Samples
}

\author{
Kevin C. Honeychurch, Joshua Brooks and John P. Hart* \\ Centre for Research in Biosciences, Faculty of Health and Life Sciences, University of the West of England, \\ Bristol, Frenchay Campus, Coldharbour Lane, Bristol, BS16 1QY, UK. \\ *Corresponding Author Tel. +44 117 3282469, Fax.+44 117 3282904, email john.hart@uwe.ac.uk
}

\section{Abstract}

This paper describes the development of an electrochemical assay based on screen-printed carbon sensors for the determination of clonazepam in serum and in wine. The cyclic voltammetric behaviour of the drug was investigated and the effects of $\mathrm{pH}$ and scan rate on the peak current and peak potential determined. Two reduction peaks were recorded on the initial negative going scan, which were considered to result from the $2 \mathrm{e}^{-}, 2 \mathrm{H}^{+}$reduction of the 4,5 -azomethine and from the $4 \mathrm{e}^{-}, 4 \mathrm{H}^{+}$reduction of the $7-\mathrm{NO}_{2}$ to a hydroxylamine. On the return positive going scan an oxidation peak was seen, which was considered to result from the $2 \mathrm{e}^{-}, 2 \mathrm{H}^{+}$oxidation (O1) of the hydroxylamine to the corresponding nitroso species. At $\mathrm{pH} 11$ the solution of clonazepam was found to turn from clear to yellow in colour and the voltammetric signal of the $\mathrm{O} 1$ oxidation process was found to be adsorptive in nature, this was exploited in the development of an adsorptive stripping voltammetric assay. Experimental conditions were then optimised for the differential pulse adsorptive voltammetric measurement of clonazepam in wine and serum samples. It was shown that these analyses could be performed on only $100 \mu \mathrm{L}$ of sample which was deposited on the sensor surface. Mean recoveries of $79.53 \%(\% \mathrm{CV}=9.88 \%)$ and $88.22 \%(\% \mathrm{CV}=14.1 \%)$ 
were calculated for wine fortified with $3.16 \mu \mathrm{g} / \mathrm{mL}$ and serum fortified with $12.6 \mu \mathrm{g} / \mathrm{mL}$ respectively.

Keywords: clonazepam, beverages, cyclic voltammetry, adsorptive stripping voltammetry, electrochemical sensor, screen-printed.

\section{Introduction}

Since the introduction of Librium ${ }^{\circledR}$ in 1960 [1], a large number of structurally similar benzodiazepine compounds have been developed and utilised widely as tranquillisers, anticonvulsants, amnestics, hypnotics, sedatives anxiolytics, [2] . They were originally regarded being safer than older drugs such as barbiturates, but still as effective. However, issues have emerged, such as dependence and withdrawal problems [3-5], and side-effects such as dizziness leading to injuries and falls in the elderly [6]. Benzodiazepines are often abused by poly-drug abusers to lengthen the "high" generated by other drugs and lessen the withdrawal problems [7-9]. Reports have highlighted their use in drug-facilitated crime (DFC), drug-facilitated sexual assaults (DFSA) [10-12]. Detectable levels have also been recently reported in potable and environmental water systems, resulting in possible toxic effects for both humans and aquatic life [13-15].

Clonazepam (5-(2-chlorophenyl)-7-nitro-2,3-dihydro-1,4-benzodiazepin-2-one, i) has been identified as one of the more common benzodiazepines that has been used illegally $[16,17]$ and has been reported in cases of sexual assault [18]. It is one of the more potent 1,4benzodiazepines and is prescribed for the treatment of a wide range of afflictions such as sleep disturbance, depression [19], anxiety and panic disorders [20], forms of parasomnia [21], obsessive-compulsive disorder [22], seizures [23], certain types of migraines [24] and epilepsy [25]. 
Studies have shown that it is possible to electrochemically determine clonazepam using a variety of different working electrode materials. Clonazepam, amongst a number of other benzodiazepines, including: flurazepam, alprazolam, midazolam, medazepam, chlordiazepoxide, and diazepam have detected in phytotherapeutic formulations at a $\mathrm{Hg}$ drop electrode exhibiting a linear range of $1.0 \times 10^{-6}$ to $30.0 \times 10^{-6} \mathrm{M}$ when utilising $\mathrm{pH} 10$ Ringer solution as the supporting electrolyte [26]. The benzodiazepines determine were divided into four separate groups according to their cathodic voltammetric behaviour allowing for the rapid voltammetric scanning of these formulations.

Recently, Martins et al [27] have reported on the determination of clonazepam, diazepam, flunitrazepam and nitrazepam at a boron doped diamond electrode (BDDE), as part of a liquid chromatographic system. Cyclic voltammetry was utilised to investigate the electrochemical behaviour of the four benzodiazepines at the BDDE in $0.1 \mathrm{M}$ phosphate buffer at $\mathrm{pH} 3.5,6.0$ and 8.0 with the optimum response obtained at $\mathrm{pH} 3.5$. Chromatographic separation was achieved at octyldecyl stationary phase utilising a mobile phase of sodium phosphate $(\mathrm{pH} 3.5 ; 0.10 \mathrm{M})$ acetonitrile $(65: 35, \mathrm{v} / \mathrm{v})$, with a flow rate of 1.2 $\mathrm{ml} / \mathrm{min}$. A thin layer amperometric detector operated in the pulse mode was used for the detection of the benzodiazepines. The optimum wave form for the reduction was reported to be $-1.9 \mathrm{~V},+1.5 \mathrm{~V}$ and $-0.5 \mathrm{~V}$, with repetition time of $0.5 \mathrm{~s}$. Detection limits of $0.5,0.6$ and $2.0 \mathrm{\mu g} / \mathrm{ml}$ were reported for nitrazepam, clonazepam and diazepam respectively. Analysis of pharmaceutical tablet formulations showed good agreement with that found by liquid chromatography with UV diode array detection.

Previously, we have determined a variety of benzodiazepines using both screen-printed carbon electrodes (SPCEs) $[28,29]$. Consequently, we considered that it should be feasible to develop an electrochemical for the determination of clonazepam, using a SPCE. 
In this paper we first discuss the cyclic voltammetric behaviour of clonazepam; we then describe the optimisation of the conditions for an adsorptive stripping voltammetric (AdSV) based assay for its quantification in beverages and serum. To our knowledge this is the first report on the redox behaviour of clonazepam using a SPCE and its electroanalytical exploitation.

\section{Experimental}

\subsection{Chemicals and Reagents}

All chemicals were obtained from Fisher (Loughborough, UK), unless otherwise stated. Deionized water was obtained from a Purite RO200 - Stillplus HP System, (Purite Oxon., UK). Solutions of disodium, trisodium, sodium o-phosphate and o-phosphoric acid were made at a concentration of $200 \mathrm{mM}$ by dissolving the appropriate mass in deionized water. These were then titrated together, to give the desired $\mathrm{pH}$. A stock solution of clonazepam (SigmaAldrich, Dorset, UK) was prepared by dissolving the required mass in ethanol to give a concentration of $10 \mathrm{mM}$. Working standards, for initial voltammetric studies, were prepared daily by dilution of this solution with phosphate buffer to give a final concentration of $100 \mathrm{mM}$ phosphate buffer containing $1 \mathrm{mM}$ clonazepam. These were then adjusted with sufficient water to give a $10 \%$ ethanol solution. A white wine beverage sample (Mannara, Grillo Pinot Grigio, Sicilia, 2008, $13 \%$ v/v) was obtained from a local commercial outlet. Foetal bovine serum was obtained from Biosera (Brambleside, UK).

\subsection{Apparatus and Instrumentation}

Cyclic and differential pulse voltammetry were performed with a Pstat10 potentiostat interfaced to a PC for data acquisition via the General Purpose Electrochemical System Software Package (GPES) version 3.4 (Autolab, Windsor Scientific Limited, Slough, Berkshire, UK). The C10903P14 ink based SPCEs were supplied by Gwent Electronic Materials Ltd 
(Pontypool, UK). The design of which has been shown elsewhere [30]. Initial studies were performed using a $10 \mathrm{~mL}$ voltammetric cell (Metrohm, Switzerland).

\subsection{Electrochemical Conditions}

Cyclic voltammograms were initially recorded with plain solutions of $0.1 \mathrm{M}$ phosphate buffer, containing $10 \%$ ethanol and then in the same solution containing $1 \mathrm{mM}$ clonazepam. Samples were purged with nitrogen (BOC, Guildford, UK) for 10 minutes to eliminate oxygen. A starting potential of $0.0 \mathrm{~V}$, an initial switching potential $-1.7 \mathrm{~V}$, second switching potential $+1.0 \mathrm{~V}$ and end potential of $0.0 \mathrm{~V}$ were utilized. A new SPCE was used for each determination. Differential pulse voltammetry was undertaken using a starting potential of $-1.5 \mathrm{~V}$ (held for $60 \mathrm{~s}$ ) and a final potential of $0.0 \mathrm{~V}$; using a step height of $10 \mathrm{mV}$, pulse repetition time $0.2 \mathrm{~s}$, pulse amplitude of $100 \mathrm{mV}$, and pulse duration of $50 \mathrm{~ms}$.

\subsection{Evaluation of the Adsorptive Stripping Voltammetric Assay}

\subsubsection{Determination of Clonazepam in Wine}

A $25 \mathrm{~mL}$ aliquot of wine fortified with $3.16 \mu \mathrm{g} / \mathrm{mL}$ of clonazepam was treated with $1.9 \mathrm{~g}$ of trisodium phosphate to produce a concentration of $0.2 \mathrm{M}$ of this salt. A $5 \mathrm{~mL}$ aliquot of this mixture was diluted with sufficient water and ethanol to give a $0.1 \mathrm{M}$ phosphate/10\% ethanol solution taking into consideration the original ethanol concentration of the wine. A $100 \mu \mathrm{L}$ aliquot of this solution was examined directly on the strip using the optimised DPAdSV conditions. The concentration of clonazepam was determined using the method of multiple standard additions. A total of six repeat samples were analysed and the recovery and precision were calculated.

\subsubsection{Determination of Clonazepam in Serum}


A $2 \mathrm{~mL}$ aliquot of serum was fortified with $12.6 \mu \mathrm{g} / \mathrm{mL}$ of clonazepam and was extracted with an equal volume of ethyl acetate by shaking by hand for 3 minutes. The two phases were allowed to separate and $1 \mathrm{~mL}$ of the resulting organic layer was taken and blown down to dryness under nitrogen at room temperature. This residue was then reconstituted in 0.5 $\mathrm{mL}$ of the optimised supporting electrolyte $(0.1 \mathrm{M} \mathrm{pH} 11$ phosphate buffer containing $10 \%$ ethanol). Aliquots of $100 \mu \mathrm{L}$ were then taken and pipetted to the screen-printed sensor surface and examined using the optimised DPAdSV conditions. The concentration of clonazepam present was determined using the method of multiple standard addition. A total of five repeat samples were analysed and the recovery and precision were calculated.

\section{Results and Discussion}

\subsection{Cyclic Voltammetric Behaviour}

Figure $1(\mathrm{~A})$ shows a typical cyclic voltammogram obtained with clonazepam at $\mathrm{pH} 7$ using a SPCE. R1 is believed to result from the $4 \mathrm{e}^{-}, 4 \mathrm{H}^{+}$reduction of the 7 -nitro group to a hydroxylamine with an associated loss of water (eq.1). The subsequent R2 process results from the $2 \mathrm{e}^{-}, 2 \mathrm{H}^{+}$reduction of the 4,5 -azomethine group (eq.2). On the return positive scan an oxidation peak $(\mathrm{O} 1)$ is obtained, resulting from the oxidation of the hydroxylamine to produce a nitroso species (eq.3). This mechanism is in agreement with that suggested recently reported by Lu et al [31]. In our study, two other oxidation peaks were obtained, which probably result from the oxidation of the $1-\mathrm{N}$ and $4-\mathrm{N}$ lone electrode pairs to form radical species.

$$
\begin{aligned}
& \mathrm{R}-\mathrm{NO}_{2}+4 \mathrm{e}^{-}+4 \mathrm{H}^{+} \rightarrow \mathrm{R}-\mathrm{N}(\mathrm{H}) \mathrm{OH}+\mathrm{H}_{2} \mathrm{O} \\
& \mathrm{R}-\mathrm{C}=\mathrm{N}-\mathrm{R}^{\prime}+2 \mathrm{e}^{-}+2 \mathrm{H}^{+} \rightarrow \mathrm{R}-\mathrm{C}(\mathrm{H})-\mathrm{N}(\mathrm{H})-\mathrm{R}^{\prime} \\
& \mathrm{R}-\mathrm{N}(\mathrm{H}) \mathrm{OH} \rightarrow \mathrm{R}-\mathrm{N}=\mathrm{O}+2 \mathrm{e}^{-}+2 \mathrm{H}^{+}
\end{aligned}
$$


When the solution was adjusted to $\mathrm{pH} 11.0$ the solution was observed to turn from colourless to yellow. Cyclic voltammetric investigations of clonazepam at this $\mathrm{pH}$ showed similar behaviour to that seen at lower $\mathrm{pH}$ values (figure 1B); however, the reduction peak $\mathrm{R} 2$ is absent. This we believe is due to base hydrolysis of the 4,5 -azomethine bond resulting in ring opening and consequently loss of this electroactive functional group. Previous studies of clonazepam have shown that the drug is unstable at both high and low $\mathrm{pH}$ producing several degradation products [32,33]; these were reported to be carbostyril and 2-amino-2'-chloro-5-nitrobenzophenone [33].

Previous studies of aromatic primary amines [34] have shown their voltammetric oxidation potentials $(+0.8 \mathrm{~V}$ to $+1.0 \mathrm{~V})$ to be much higher than that of the hydroxylamine studied in this investigation. Consequently, we do not believe that the principal biological metabolite, 7-amino-clonazepam would interfere with our determination of clonazepam.

\subsection{Effect of pH and Scan Rate}

At each $\mathrm{pH}$ value investigated we explored the effect of scan rate $(v)$, over the range 20 to $200 \mathrm{mV} / \mathrm{s}$, on the cyclic voltammetric behaviour of clonazepam. The peak potentials for both reduction peaks, $\mathrm{R} 1$ and $\mathrm{R} 2$ were found to be linearly dependent with $\mathrm{pH}$. A plot of Ep vs. $\mathrm{pH}$ between $\mathrm{pH} 3$ and 9 produced a slope of $50 \mathrm{mV} / \mathrm{pH}$, close to the theoretical value expected for a reduction process involving an equal number of protons and electrons. However, at higher $\mathrm{pH}$ values $\mathrm{Ep}$ values for both peaks were not found to follow the predicted slope and were considered to result from the reduction of a base hydrolysis product rather than clonazepam itself.

The Ep vs. $\mathrm{pH}$ plot for the oxidation peak $\mathrm{O} 1$ was found to give a slope of $60 \mathrm{mV} / \mathrm{pH}$, indicative of an oxidation process involving an equal number of protons and electrons. The effect of scan rate on the magnitude of $i_{\mathrm{p}}$ was examined over the $\mathrm{pH}$ range $3-11$. The 
current function vs. $\mathrm{pH}$ was plotted for each $\mathrm{pH}$ value and the plot obtained with $\mathrm{pH} 11$ is shown in figure 2 . Clearly this exhibited a positive slope which indicates reactant adsorption at the SPCE surface. This adsorptive behaviour is very attractive analytically as it may be exploited to enhance sensitivity by developing an adsorptive stripping voltammetric assay for clonazepam. Consequently, further investigations were undertaken to explore this possibility.

\subsection{Effect of Accumulation Potential}

Figure 3 shows the effect of accumulation potential on the result peak current $\left(i_{\mathrm{p}}\right)$ magnitude of $\mathrm{O} 1$ obtained by differential pulse voltammetry using an accumulation time of $60 \mathrm{~s}$ using an $80 \mu \mathrm{M}$ clonazepam solution. A near linear relationship with applied potential was gained between -0.9 and $-1.5 \vee(v s$. $\mathrm{Ag} / \mathrm{AgCl})$ followed by a plateau. Further studies were made using an applied potential of $-1.5 \mathrm{~V}$ (vs. $\mathrm{Ag} / \mathrm{AgCl})$.

\subsection{Effect of Accumulation Time}

Figure 4 shows the effect of increasing accumulation time at an applied potential of $-1.5 \mathrm{~V}$ for the same differential pulse voltammetric conditions and concentration as above. The resulting oxidation stripping peak was found to increase with time until $240 \mathrm{~s}$. In order to avoid complete monolayer of the SPCE surface which would result in unreliable data we chose an accumulation time of $60 \mathrm{~s}$ for further studies.

\subsection{Effect of Sample Volume}

In previous studies we have shown that it was possible to use $\mu \mathrm{L}$ sample volumes for the determination of other benzodiazepines [28] and nitroaromatics compounds [35]. As it was our goal to apply these devices in the area of bioanalysis and forensic investigations, where the collection of large sample volumes can be problematic, we investigated the possibility of using a similar approach. Consequently, to investigate the possibility of using such a system 
the effect of dissolved oxygen in solution, and sample size on the anodic peak (O1) was examined. It was found possible to use non-degassed samples of only $100 \mu \mathrm{L}$ which could be deposited directly onto the surface of the SPCE, ensuring both the working and pseudoreference/counter electrodes were covered. The small sample size and the presence of oxygen, had no effect on the voltammetric response, therefore, in further studies sample volumes of $100 \mu \mathrm{L}$ were used.

\subsection{Calibration curve and limit of detection}

At this point we decided to use the more sensitive differential pulse waveform [29] for quantitative measurements of clonazepam. Initial studies were undertaken to study the effect of clonazepam concentrations on the magnitude of the differential pulse adsorptive stripping peak 01 occurring at a potential of $-0.6 \mathrm{~V}$. The calibration plot was linear over the range $2.05-8.00 \mu \mathrm{g} / \mathrm{mL}\left(R^{2}=0.984\right)$, with a sensitivity of $21.8 \mathrm{nA} / \mu \mathrm{g} / \mathrm{mL}$; above this concentration the response was found to show curvature as a monolayer is approached. The theoretical detection limit, defined as three times the mean baseline noise was calculated to be $1.96 \mu \mathrm{g} / \mathrm{mL}$. A coefficient of variation of $7.4 \%$ was obtained for a $7.1 \mathrm{mg} / \mathrm{L}$ solution of clonazepam.

\section{Analytical Application}

\subsection{Determination of Clonazepam in Wine}

The proposed screen-printed carbon sensors were evaluated by carrying out clonazepam determinations on white wine (Mannara, Grillo Pinot Grigio, Sicilia, 2008, 13 \% v/v) before and after spiking with clonazepam at a concentration of $3.16 \mu \mathrm{g} / \mathrm{mL}$. The deposition time and potential, as well as DPAdSV parameters were the same as used previously. The concentration of clonazepam was determined using the method of multiple standard additions and Figure 5 shows the effect of added standards to a typical white wine sample. 
Table 1 shows the precision and recovery data that we obtained on the wine samples. These data demonstrate that the proposed method has promise for the determination of clonazepam in such samples.

\subsection{Determination of Clonazepam in Serum}

Serum samples were first extracted with ethyl acetate and then reconstituted in the optimised supporting electrolyte. These were then measured in the same manner as described for the white wine samples (figure 6). The precision and recovery data obtained for a serum sample spiked with $12.6 \mu \mathrm{g} / \mathrm{mL}$ is shown in table 2 . This concentration of drug could arise as a result of accidental or deliberate overdose; consequently, our adsorptive stripping voltammetric assay would be applicable to identifying and quantifying the drug for such situations.

\section{Conclusions}

A simple and rapid method for the determination of clonazepam in wine and serum samples by DPAdSV in conjunction with SPCE sensors has been successfully developed. Using an applied potential of $-1.5 \mathrm{~V}$ for $60 \mathrm{~s}$, concentrations as low as $2.0 \mathrm{mg} / \mathrm{L}$ could be readily be determined in white wine and serum. A theoretical detection limit of $1.96 \mu \mathrm{g} / \mathrm{mL}$ was found which is an improvement on that reported by Latorre et al [36] at a glassy carbon electrode. Previous polarographic studies have demonstrated lower limits of detection, but have required the use of $\mathrm{Hg}$ working electrodes [37,38]. More recent reports have utilised modifications of the working electrode surface such as with silver nanoparticle/multi walled carbon nanotube nanocomposites [39]. However, we do not feel that this approach will allow for mass production that has been shown by screen-printing $[40,41]$. The proposed method gives reliable results using the standard addition method. In future studies we will 
investigate the possibility of using this technique to determine other drugs and nitro compounds.

\section{Acknowledgements}

The authors would like to thank the HEFCE for funding. They are grateful to Gwent Electronic Materials Ltd for supplying the screen-printed sensors. 


\begin{tabular}{|c|c|c|c|}
\hline \multicolumn{2}{|l|}{ White Wine } & \multicolumn{2}{l|}{} \\
\cline { 1 - 4 } $\begin{array}{l}\text { Original concentration } \\
(\mu \mathrm{g} / \mathrm{mL})\end{array}$ & $\begin{array}{l}\text { Fortified Concentration } \\
(\mu \mathrm{g} / \mathrm{mL})\end{array}$ & Detected Concentration $(\mu \mathrm{g} / \mathrm{mL})$ & $\begin{array}{l}\text { Recovery } \\
(\%)\end{array}$ \\
\hline ND & 3.16 & 2.44 & 77.4 \\
\hline ND & 3.16 & 2.67 & 84.6 \\
\hline ND & 3.16 & 2.62 & 82.9 \\
\hline ND & 3.16 & 2.66 & 84.4 \\
\hline ND & 3.16 & 2.45 & 77.7 \\
\hline ND & 3.16 & 2.87 & 90.9 \\
\hline ND & 3.16 & 2.66 & 84.4 \\
\hline & & & 83.2 \\
\hline & & Mean & 4.62 \\
\cline { 3 - 4 } & & Standard Deviation & 5.6 \\
\cline { 3 - 4 } & & Coefficient of Variation & \\
\hline
\end{tabular}

Table 1. Recovery and precision data for clonazepam obtained on white wine samples, ND = not detected.

\begin{tabular}{|c|c|l|c|}
\hline \multicolumn{1}{|c|}{ Serum } & \multicolumn{2}{|c|}{$\begin{array}{c}\text { Fortified Concentration } \\
(\mu \mathrm{g} / \mathrm{mL})\end{array}$} & $\begin{array}{c}\text { Detected Concentration }(\mu \mathrm{g} / \mathrm{mL}) \\
(\%)\end{array}$ \\
\hline ND & 12.63 & 11.38 & 90.1 \\
\hline ND & 12.63 & 9.69 & 76.7 \\
\hline ND & 12.63 & 9.17 & 72.6 \\
\hline ND & 12.63 & 13.50 & 106.9 \\
\hline ND & 12.63 & 11.97 & 94.8 \\
\hline & & & $\mathbf{8 8 . 2}$ \\
\hline & & Mean & 13.9 \\
\cline { 3 - 4 } & & Standard Deviation & 15.8 \\
\cline { 3 - 4 } & & Coefficient of Variation & \\
\hline
\end{tabular}

Table 2. Recovery and precision data for clonazepam obtained on bovine serum samples, ND = not detected. 


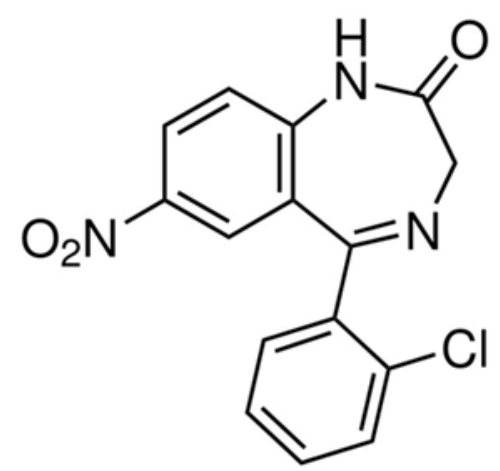

(i) 

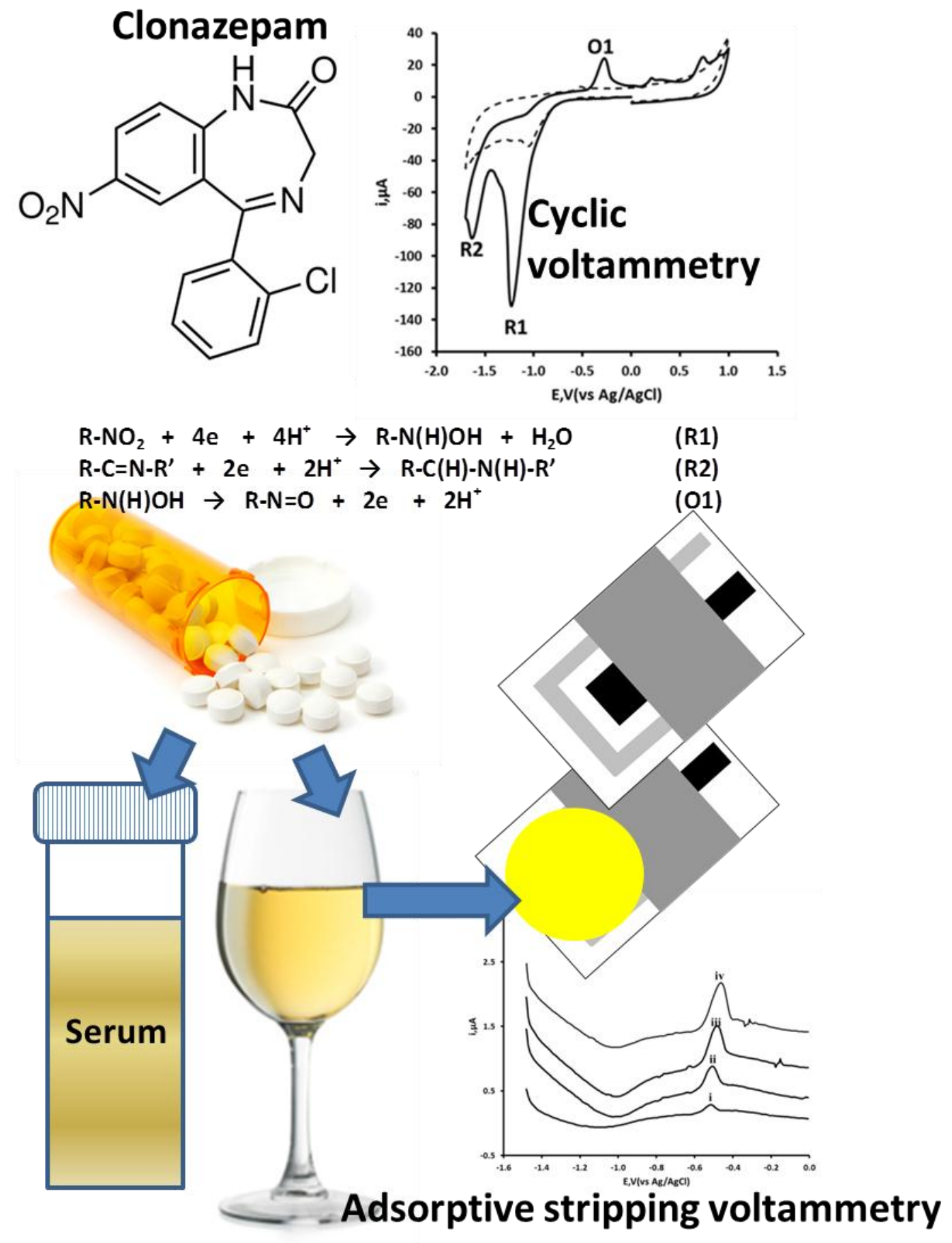
(A)

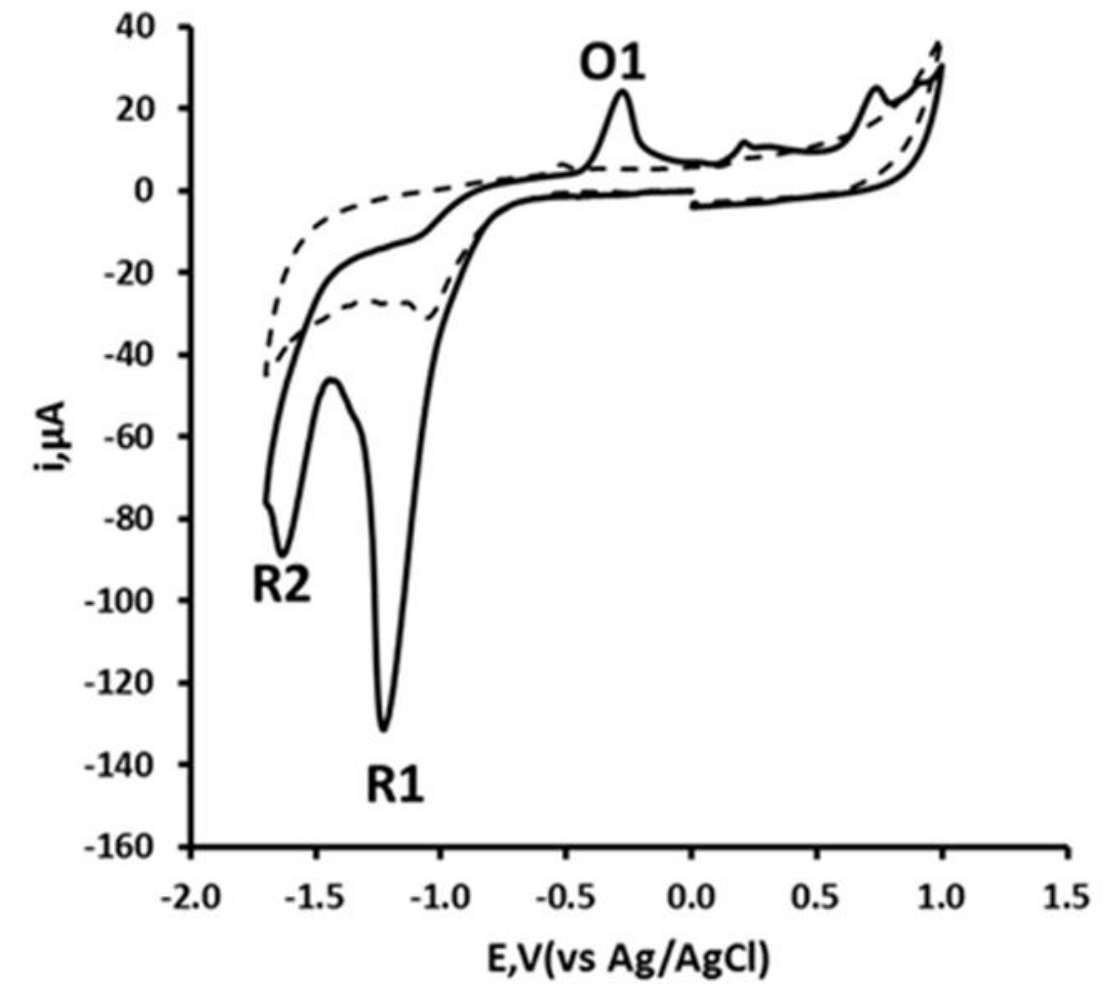

(B)

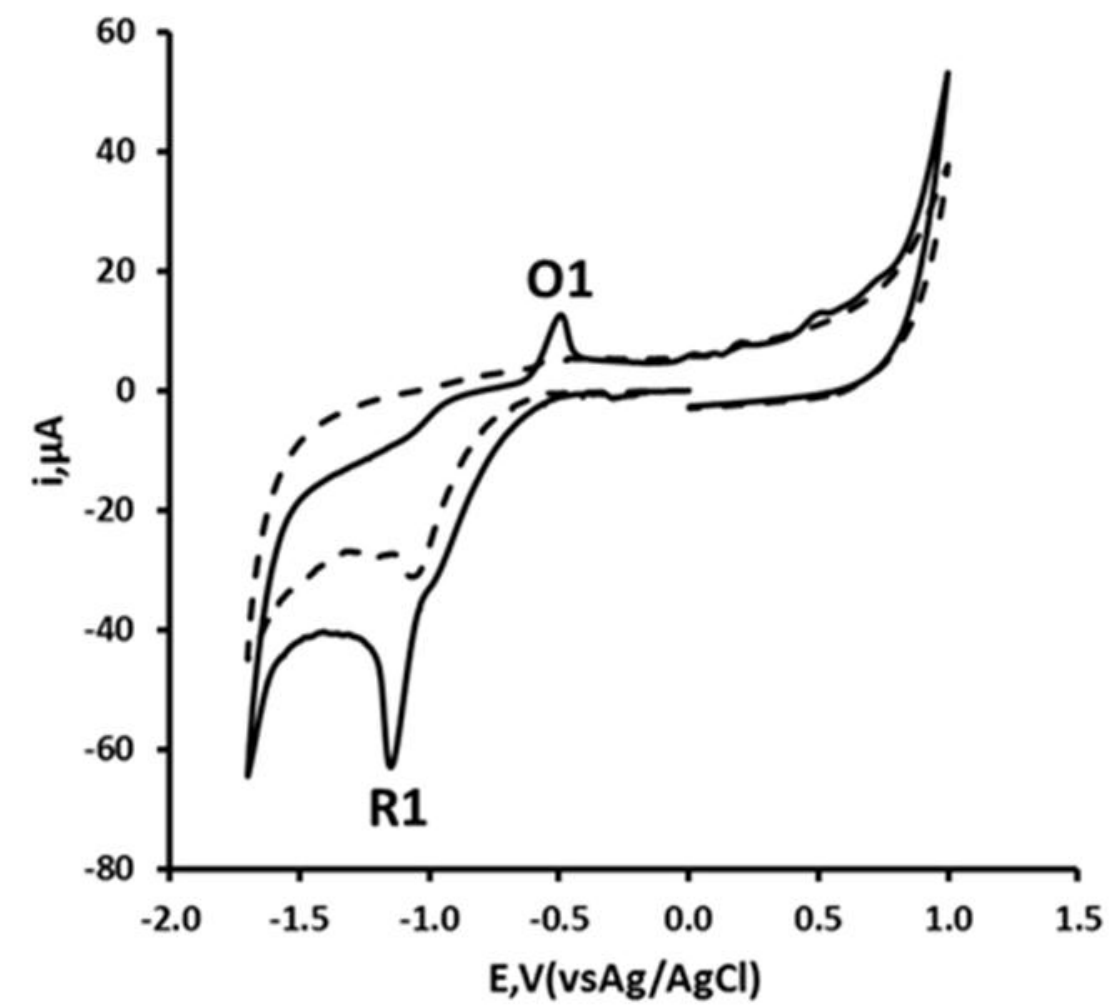

Figure 1. Cyclic voltammogram obtained using a scan rate of $50 \mathrm{mV} / \mathrm{s}$ with $10 \%$ ethanol, $0.1 \mathrm{M}$ phosphate at (A) pH 7.0 and (B) pH 11 , dashed line in the absence of and solid line in the presence of $1 \mathrm{mM}$ clonazepam. Voltammetric conditions: starting potential $0.0 \mathrm{~V}$, initial switching, $1.7 \mathrm{~V}$ and second switching potential $+1.0 \mathrm{~V}$. 


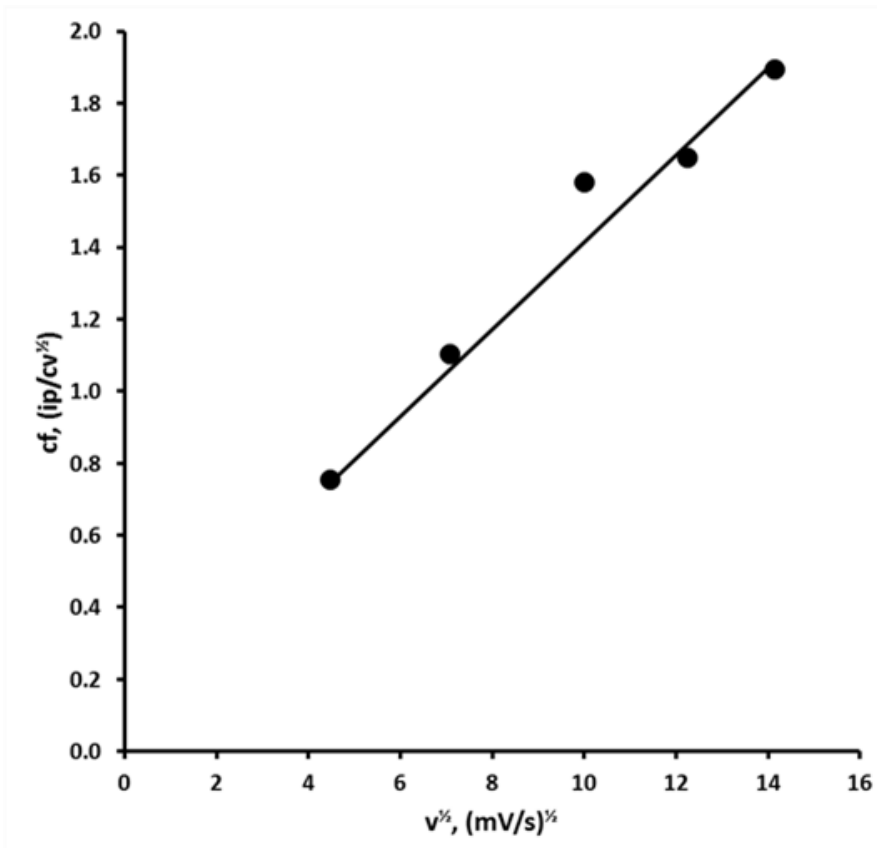

Figure 2. Current function plot for $\mathrm{pH} 1101$ peak.

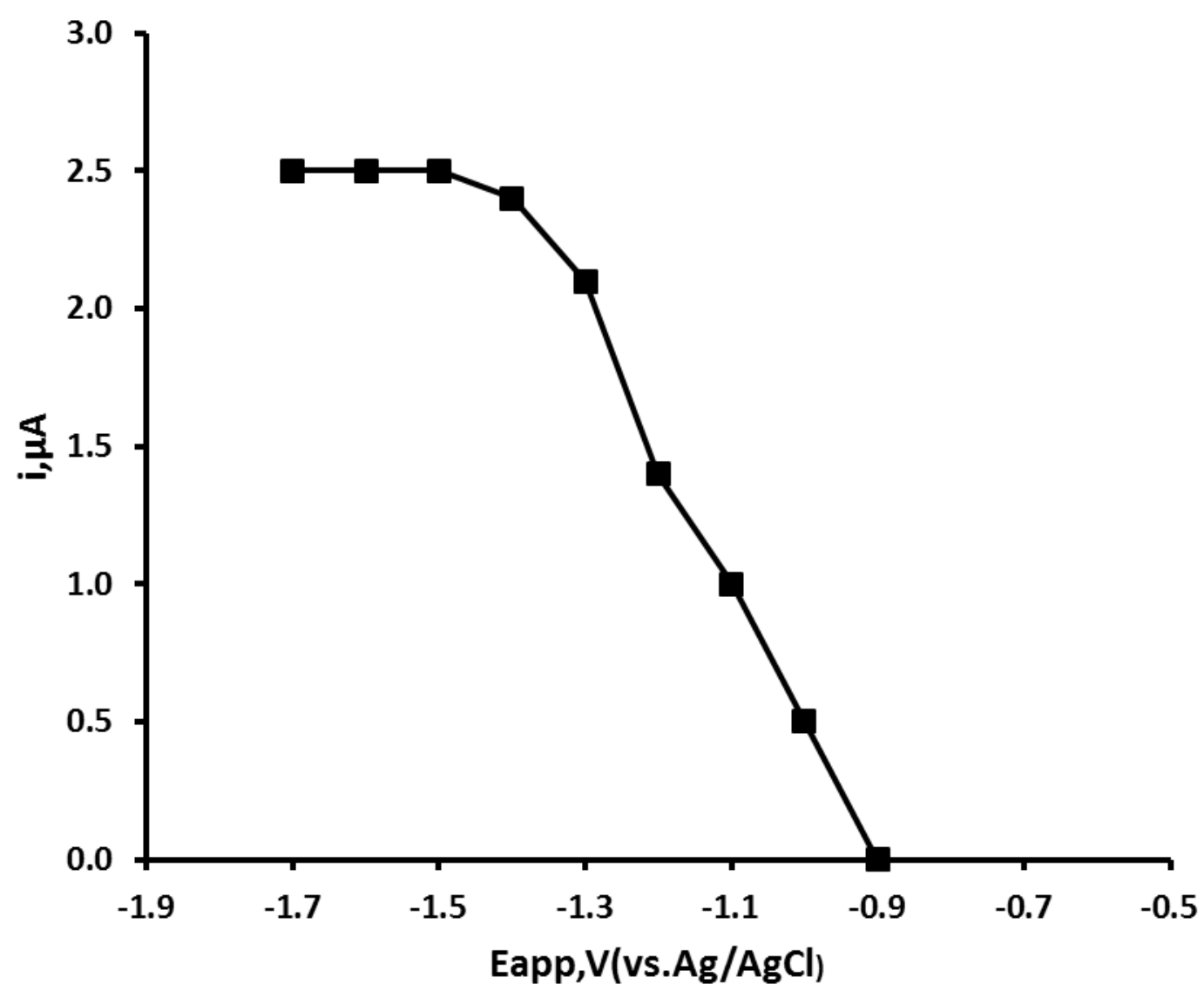

Figure 3. Effect of accumulation potential on $0.1 \mathrm{mM}$ clonazepam 01 oxidation peak obtained by linear sweep voltammetry at $\mathrm{pH} 11$. A new SPCE was used for each determination. 


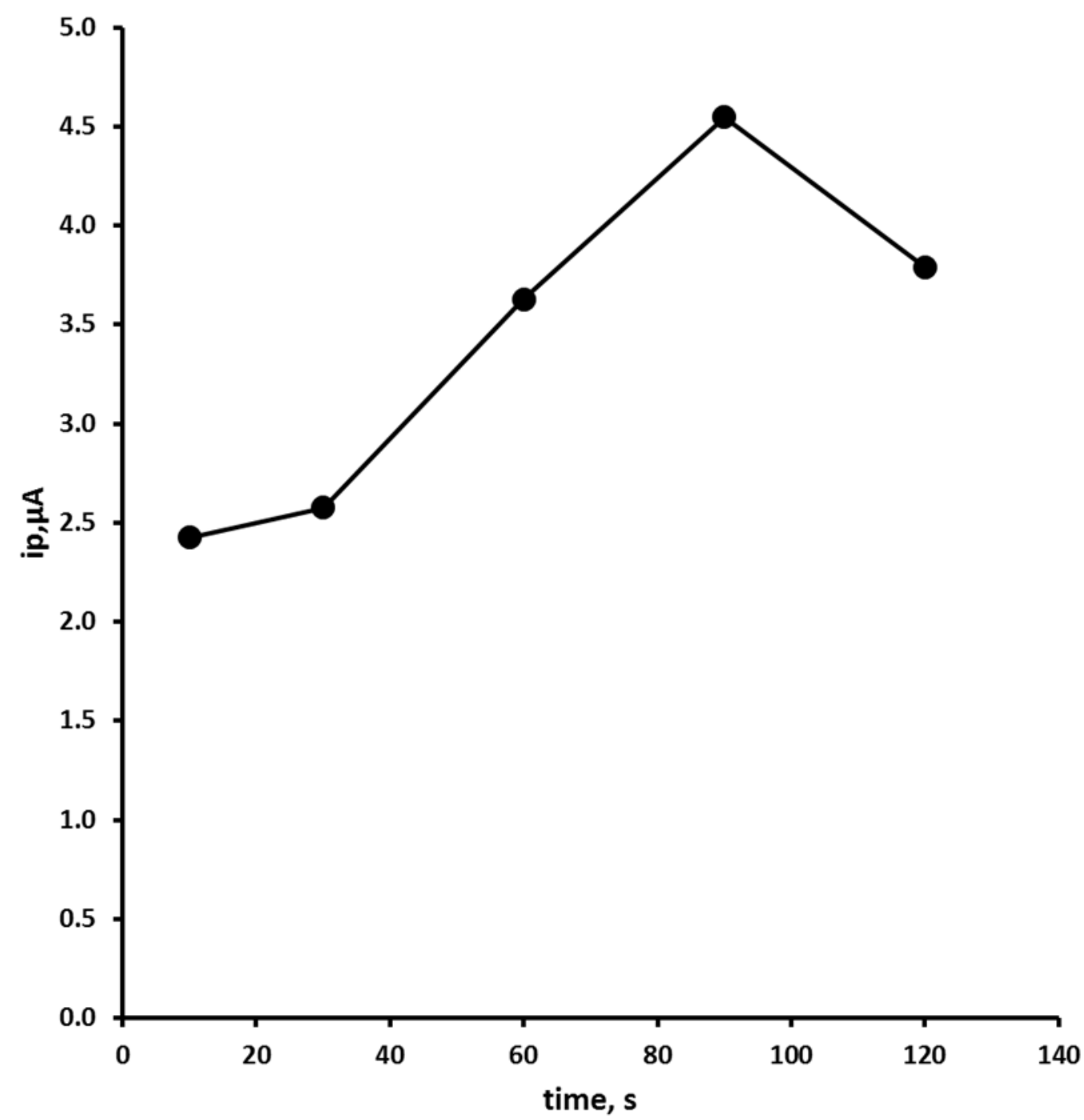

Figure 4. Effect of accumulation time on $0.1 \mathrm{mM}$ clonazepam 01 oxidation peak obtained by linear sweep voltammetry at $\mathrm{pH} 11$. A new SPCE was used for each determination. 


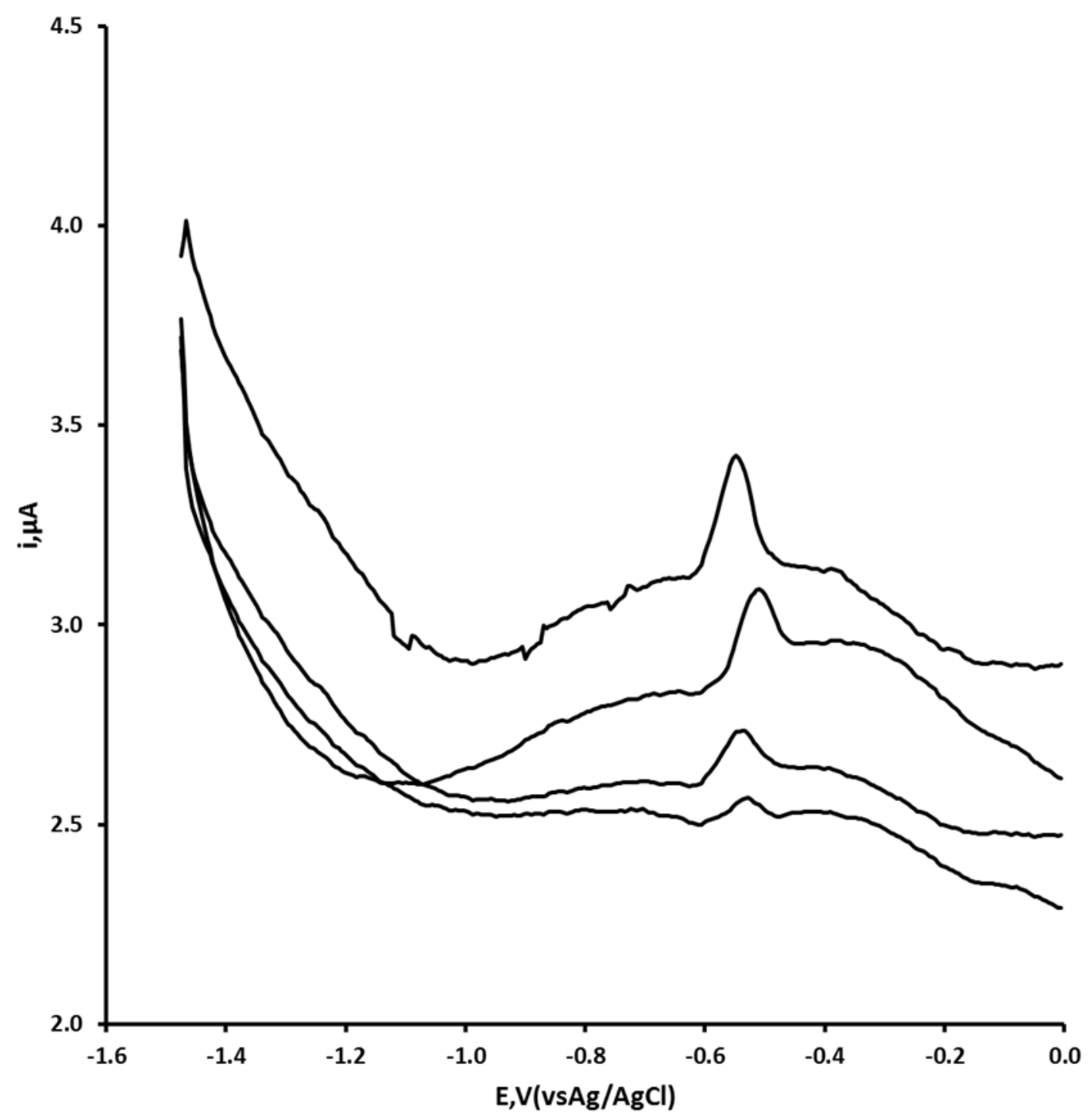

Figure 5. Adsorptive stripping voltammetry of white wine fortified with $3.16 \mu \mathrm{g} / \mathrm{mL}$ clonazepam. Standard addition of (i) $0 \mu \mathrm{M}$ (ii) $10 \mu \mathrm{M}$, (iii) $20 \mu \mathrm{M}$ and (iv) $30 \mu \mathrm{M}$. Conditions: $-1.5 \mathrm{~V}$ for $60 \mathrm{~s}, 100 \mu \mathrm{L}$ sample volume. A new SPCE was used for each determination. 


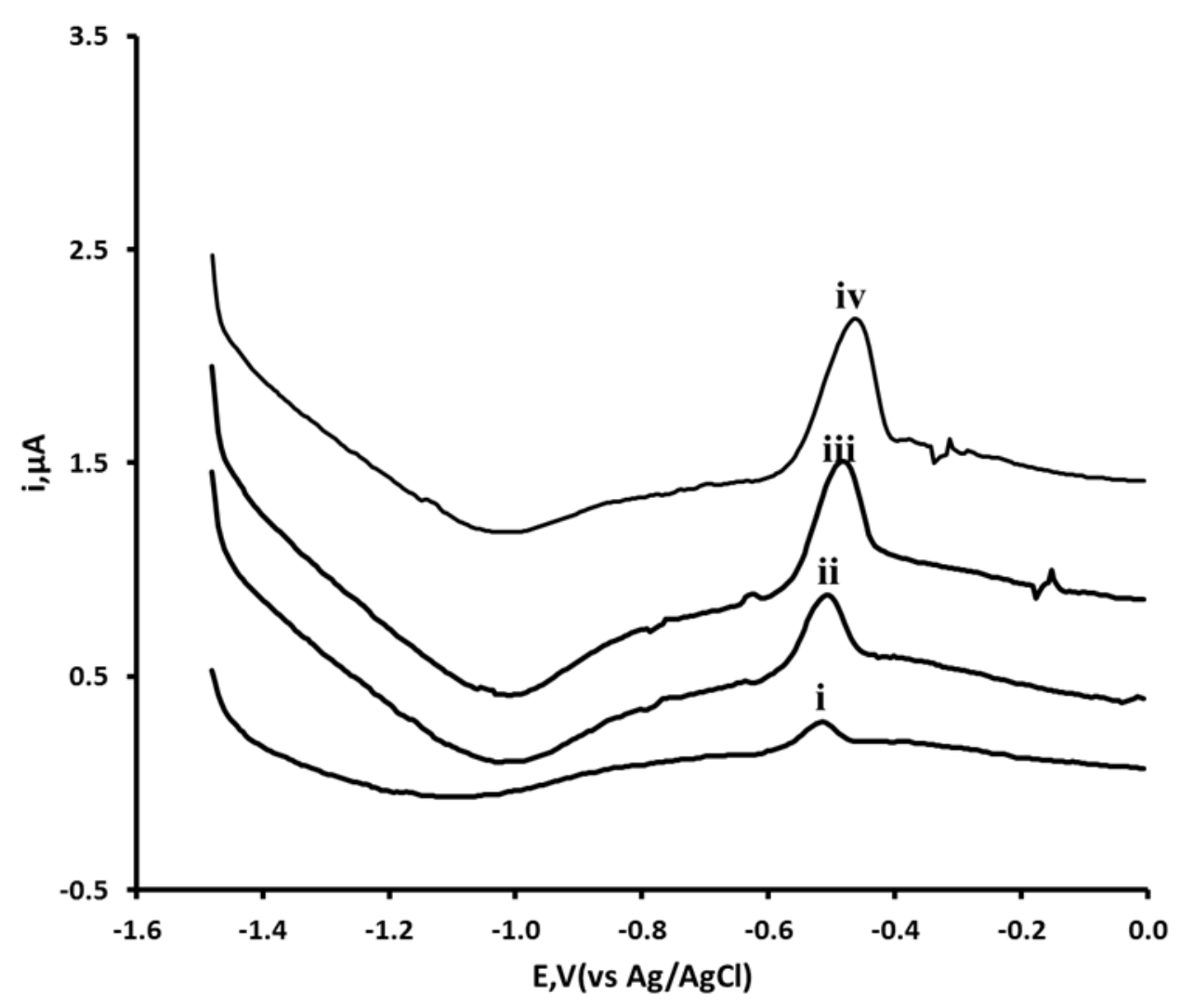

Figure 6. Adsorptive stripping voltammetry of serum fortified with $12.63 \mu \mathrm{g} / \mathrm{mL}$ clonazepam. Standard addition of (i) $0 \mu \mathrm{g} / \mathrm{mL}$ (ii) $3.16 \mu \mathrm{g} / \mathrm{mL}$, (iii) $6.31 \mu \mathrm{g} / \mathrm{mL}$ and (iv) $9.47 \mu \mathrm{g} / \mathrm{mL}$. Conditions: -1.5 $\checkmark$ for $60 \mathrm{~s}, 100 \mu \mathrm{L}$ sample volume. A new SPCE was used for each determination.

\section{References}

[1] L.O. Randall, Pharmacology of chlordiazepoxide (Librium). Dis. New. Syst. 22 (1961) (Suppl 7) 15.

[2] J. Riss, J. Cloyd, J. Gates, S. Collins, Benzodiazepines in epilepsy: pharmacology and pharmacokinetics, Acta Neurol. Scand. 118 (2008) 69-86.

[3] M. Lader, Benzodiazepines - Panacea or Poison? Aust. N. Z. J. Psychiatry (1981) 151-159.

[4] J. Donoghue, M. Lader, Usage of benzodiazepines: A review, Int. J. Psychiat. Clin. 14 (2010) 78-87.

[5] M. Lader, Benzodiazepine Dependence, Int. Rev. Psychiatr. 1 (1989) 149-156.

[6] M.H. Lader, Limitations on the use of benzodiazepines in anxiety and insomnia: are they justified? Eur. Neuropsychopharm. 9 (1999) Suppl. 6 S399-S405.

[7] S.C. Licata, J.K. Rowlett, Abuse and dependence liability of benzodiazepine-type drugs: GABA(A) receptor modulation and beyond. Pharmacol. Biochem. Behav. 90 (2008) (1) 74-89.

[8] L.P. Longo, B. Johnson, Addiction: Part I. Benzodiazepines-Side Effects, Abuse Risk and Alternatives, Am. Fam. Physician 61 (2000) (7), 2121-2128.

[9] C.H. Ashton, Benzodiazepine Abuse. Drugs and Dependence, (Harwood Academic Publishers, New York, New York, 2002), pp. 197-212.

[10] S. Djezzar, F. Questel, E. Burin, S. Dally, Chemical submission: results of 4-year French inquiry, Int. J. Legal Med. 123 (2000), 213-219.

[11] M. Scott-Ham, F.C. Burton, Toxicological findings in cases of alleged drug-facilitated sexual assault in the United Kingdom over a 3-year period, J. Clin. Forensic Med. 12 (2005) 175-186. 
[12] B. Madea, F. Mußhoff, Knock-Out Drugs: Their Prevalence, Modes of Action, and Means of Detection, Dtsch. Arztebl. Int. 106 (2009) 341-347.

[13] V. Calisto, V.I. Esteves, Psychiatric Pharmaceuticals in the Environment, Chemosphere 77 (2009) 1257-1274.

[14] A.C. Collier, Pharmaceutical Contaminants in Potable Water: Potential Concerns for Pregnant Women and Children, EcoHealth 4 (2007) 164-171.

[15] D. Pascoe, W. Karntanut, C.T. Müller, Do Pharmaceuticals Affect Freshwater Invertebrates? A Study with the Cnidarian Hydra vulgaris, Chemosphere, 51 (2003) 521-528.

[16] E. Fraugera, S. Nordmann, V. Orleans, V. Pradel, V. Pauly, X. Thirion, J. Micallef, Which psychoactive prescription drugs are illegally obtained and through which ways of acquisition? About OPPIDUM survey, Fundam. Clin. Pharm. 26 (2012) 549-556.

[17] L.P. Longo, B. Johnson, Addiction. Part I. Benzodiazepines-side effects. Abuse Risk and Alternatives, Am. Fam. Phys. 61 (2000) 2121-2128.

[18] A. Negrusz, R.E. Gaensslen, Analytical developments in toxicological investigation of drugfacilitated sexual assault, Anal. Bioanal. Chem. 376 (2003) 1192-1197.

[19] P.D. Londborg, W.T. Smith, V. Glaudin, J.R. Painter, Short-term cotherapy with clonazepam and fluoxetine: anxiety, sleep disturbance and core symptoms of depression. J. Affect. Disord. 61 (2000) 73-79.

[20] B. Zamiri, H.R. Eftekharian, N. Arasteh, Clonazepam for the Management of Anxiety Associated with Oral Surgery: A Randomized Double-blind Controlled Trial, J. Dent. Shiraz Univ. Med. Scien. 13 (2012) 75-79.

[21] C.H. Schenck, I. Arnulf, M.W. Mahowald, Sleep and Sex: What Can Go Wrong? A Review of the Literature on Sleep Related Disorders and Abnormal Sexual Behaviors and Experiences, Sleep 30 (2007) 683-702.

[22] W.A. Hewlett, S. Vinogradov, W.S. Agras Clomipramine, clonazepam, and clonidine treatment of obsessive-compulsive disorder, J. Clin. Psychopharmacol. 12 (1992) 420-430.

[23] T.R. Browne Clonazepam. A review of a new anticonvulsant drug. Arch. Neurol. 33 (1976) 326-32.

[24] Bisdorff, A. R. Management of vestibular migraine, Ther. Adv. Neurol. Disord. 4 (2011) 183191.

[25] Y. Ståhl, A. Persson, I. Petters, A. Rane, K. Theorell, P. Walson, Kinetics of clonazepam in relation to electroencephalographic and clinical effects. Epilepsia 24 (1983) 225-31.

[26] L.M.D. Carvalho, D. Correia, S.C. Garcia A.V.D. Bairros, P.C.D. Nascimento D. Bohrer, A new method for the simultaneous determination of 1,4-benzodiazepines and amfepramone as adulterants in phytotherapeutic formulations by voltammetry, Forensic Sci. Int. 202 (2010) 75-81.

[27] I. Martins, L.d.S. Canaes K.M. Doretto S. Rath, Boron-Doped Diamond Electrode Coupled to Liquid Chromatography: Application to Simultaneous Determination of Benzodiazepines, Electroanalysis, 22, (2010) 455-462.

[28] N.D. McGuire, K.C. Honeychurch, J.P. Hart, The Electrochemical Behaviour of Nitrazepam at a Screen-printed Carbon Electrode and Its Determination in Beverages by Adsorptive Stripping Voltammetry, Electroanalysis, 21 (2009) 2165-2170.

[29] K.C. Honeychurch, A. Crew, H. Northall, S. Radbourne, O. Davies, S. Newman, J.P. Hart, The redox behaviour of diazepam (Valium) using a disposable screen-printed sensor and its determination in drinks using a novel adsorptive stripping voltammetric assay, Talanta 116 (2013) 300-307.

[30] K.C. Honeychurch, L. Gilbert, J.P. Hart, Electrocatalytic behaviour of citric acid at a cobalt phthalocyanine-modified screen-printed carbon electrode and its application in pharmaceutical and food analysis, Anal. Bioanal. Chem. 396 (2010) 3103-3111. 
[31] M. Lu, C. Wolf, W. Cui, H. Chen, Investigation of some biologically relevant redox reactions using electrochemical mass spectrometry interfaced by desorption electrospray ionization, Anal. Bioanal. Chem. 403 (2012) 355-365.

[32] R.B. Kakde, D.D. Satone, K.K. Gadapayale, M.G. Kakde, Stability-Indicating RP-HPLC Method for the Simultaneous Determination of Escitalopram Oxalate and Clonazepam, J. Chromatogr. Sci. 51 (2013) 490-495.

[33] L.I. Bebawy, N.El Kousy Stability-Indicating Method for the Determination of Hydrochlorothiazide, Benzydamine Hydrochloride and Clonazepam in the Presence of Their Degradation Products, Anal. Lett. 30 (1997) 1379-1397.

[34] J.P. Hart, M.R. Smyth, W.F. Smyth, Voltammetric Determination of 2-, 3- and 4-Chloroaniline in Mixtures. Analyst,106 (1981) 146-152.

[35] K.C. Honeychurch, J.P. Hart, P.J. Pritchard, S. Hawkins, N.M. Ratcliffe, Development of an electrochemical assay for 2,6-dinitrotoluene, based on a screen-printed carbon electrode, and its potential application in bio-analysis, occupational and public health. Biosensors and Bioelectronics, 19 (2003) 305-312.

[36] C. Latorre, M.H. Blanco, E.L. Abad, J. Vicente, L. Hernandez, Determination of Clonazepam by Flow Injection Analysis, Analyst, 113 (1988) 317-319.

[37] A. Zapardiel, J. Lopez, E. Bermejo, L. Hernandez, Voltammetric Studies of Psychotropic-Drugs with Nitro-Groups Determination of Clonazepam in Urine by Adsorptive Stripping Voltammetry, Anal. Lett. 24 (1991) 24, 233-248.

[38] P.C.R. Kumar, K. Balaji, M. Pushpalatha, C. Sridevi, C.S. Reddy, Electro chemical study and polarographic assay of Clonazepam formulations, Der Pharmacia Lettre, 3 (2011) 311-319.

[39] B. Habibi, M. Jahanbakhshi, Silver nanoparticles/multi walled carbon nanotubes nanocomposite modified electrode: Voltammetric determination of clonazepam, Electrochim. Acta 118 (2014) 10-17.

[40] K.C. Honeychurch, Thick-film biosensors. In: Prudenziati, M. and Hormadaly, J., eds. (2012) Printed Films Materials Science and Applications in Sensors Electronics and Photonics. 1. UK: Woodhead Publishing.

[41] K.C. Honeychurch, Screen-printed electrochemical sensors and biosensors for monitoring metal pollutants. Insciences Journal, 2 (2012) 2 1-51. 